\title{
The Study of the Developments of General Education in Chinese and Western Universities
}

\author{
Xiaoyao Luo ${ }^{1, \dagger}$, Jingwen Qian ${ }^{2, *}, \dagger$, Xiaotong Song ${ }^{3, \dagger}$ \\ ${ }^{1}$ Department of Dramatic Literature, Shanghai Theatre Academy, 200040, Shanghai, China \\ ${ }^{2}$ School of Translation, Hebei Normal University, Xi'an, 710016, Shaanxi Province, China \\ ${ }^{3}$ School of Music Play, Jiangsu Normal University, Xuzhou, 221000, Jiangsu Province, China \\ ${ }^{*}$ Corresponding author. Email: lilian@mail.cu.edu.kg \\ Those authors contributed equally.
}

\begin{abstract}
According to relevant literatures, this review paper compares the western and Chinese developments of general education in colleges and universities in the curriculum goal, curriculum setting, teaching practice, organization and management on the similarities and differences. Also, this paper reviews the developments with specific cases, points out the current difficulties faced by the education mode, course system, teachers and the independent innovation ability, which is insufficient. According to the development stage, this paper summarizes the developments of general education in China and its reasons. In addition, it indicates the cultivation objectives, philosophy, curriculum structure, practice mode, evaluation mechanism and other key points that should be paid attention during its implications in China.
\end{abstract}

Keywords: General education, Comparison of Chinese and western, General education in China, University education.

\section{INTRODUCTION}

General education has a long history in the West countries such as in the U.S. In recent years, it has gradually attracted the attention of Chinese universities, playing an important role in the cultivation of qualified college students and education research. Therefore, it is of great significance to deeply compare and study the research status and development of Chinese and Western general education in universities. This report aims to explore three issues, namely, 1) the research status and comparison of the development of general education in China and the West; 2) the difficulties in the implementation of general education in China; 3) the causes and prospects for the development of general education in China. This study compares and studies the status of general education in China and the West in terms of time, implementation cases and significance. It points out six difficulties faced by universities in the implementation of general education in China, and analyzes the causes of the difficulties, forecasting the development of general education in China. This thesis will give a detailed introduction to the above content in the main body.

\section{DEVELOPMENT SITUATION AND COMPARISON OF GENERAL EDUCATION IN CHINA AND THE WEST}

\subsection{Comparisons of Development Time}

Compared with the development of general education in Chinese and western countries in universities, western general education activities have been promoted in an organized operation mode since 1828. During the overall development process, some educators and scholars, civil leaders, institutional organizations, schools and students have promoted the development of western general education activities. Among colleges and universities in Europe and the United States, from the early 1970s to the mid-1980s, British scholars have discussed general education, including Western general education activities. Through a series of research, investigations and comments, it is shown that conducting Chinese and Western general education activities should reflect on why this is done rather than blind investment.

Since the 19th century, general education activities 
in North American universities have been promoted, general educators, general educators and experts in other fields that western general education plays an important role in the overall education activities, general education in western colleges and universities is developed by the formal system and informal western general education activities. Under the influences of these general education activities, corresponding organizations began to flourish, with volunteers advocating gathered to share different cultures. After learning experience from North America, the first national research conference was the turning point, attracting more than 130 unprofessional Western general educators, funders, teachers and students. However, the development of general education in Chinese universities was obviously backward. It was not until around 1980 that China began to advocate "education about quality". Although China's general education is developed on the basis of western general education, there is still a big gap between China's general education and general education in the West.

\subsection{Case Comparisons on the Implementation of General Education in Chinese and Western Universities}

The comparison cases involve several Chinese and western universities. In the following section, we will take Peking University, Nanjing University, Shantou University and Yangzhou University with Harvard University, University of Chicago and Columbia University as examples.

Although the "research on the implementation of general education and strategy" can be concluded, during the implementation of general education in China, by 1990 , specialized university general education began published quarterly, the early journals discussed the practice of general education [1]. They provide valuable descriptions of general education through the spread of practice and plain text, in which general education activities played an important role in higher education. It is mentioned in this paper that although British universities have long put forward the theory of general education, the development process of general education activities in British universities lags behind North American universities due to historical, social and economic reasons.

At the same time, in terms of the implementation of general education, Chinese universities have added more compulsory courses in the teaching practice, which was time-consuming, and the examination requirements are higher than those of western universities. On the other hand, the teaching practice of Chinese university general education courses is few with low requirements, and even only stay in the stage of open class. In the implementation of general education in colleges and universities, western universities have a long history of general education training system, from the $1830 \mathrm{~s}$, Sweden, Norway, Denmark began to appear the earliest general education schools, but after war trauma, depression, until the end of World War II, western general education related schools and active again. They wanted students in higher education to choose to study and see equal opportunities as the most important. In the 1960s, the government began to invest a lot of fundings to support the establishment of general education universities, we see now in the western development of some western general education schools: such as Harvard University, the University of Chicago, Columbia University. These universities lay the foundation for cultivating western students' general education, in nearly forty years have trained more than six thousand students every year. Not only that, the Western general education activities in Australia and New Zealand covered a wide range of practical activities and diversified cultural traditions and general education schools, which reflected and enriched the college cultural life of local college students in conducting general education.

\subsection{Comparisons and Summary of the Implementation of General Education in Chinese and Western Universities}

After analyzing the goal of the course, general education in Western universities is clear in terms of overall teaching objectives and sub objectives of each course and is detailed in description. The goals of general education courses in Chinese universities are not clear. In addition, Chinese universities cannot accurately tell the relationship between general education and universities. When analysing curriculum settings, the first section in the curriculum is the basic skills class, and the second is the humanities and natural sciences class. The course of general education in Western universities mainly consists of these two categories, aiming to improve students' comprehensive ability and expand their horizons. General education in Chinese universities is mainly compulsory courses and cultural quality elective courses. Compared with western universities, they pay more attention to the transfer of curriculum knowledge and students' acceptance, which is not easy to motivate students. Analysis from the practice of teaching, there are many kinds of general education courses in western countries with fewer classes and high curriculum requirements; therefore, students need to spend a lot of time to complete information access and other related work after class. Chinese colleges and universities take more compulsory courses in general education teaching practice, and occupy more time, and the examination requirements are higher than those of western universities. However, from another aspects, the teaching practice of general education courses in Chinese universities has fewer cultural quality courses, lower requirements than 
western universities, and even open volume examinations or lectures. Analysis from the management western colleges and universities pay more attention, and there are relevant administrative departments for general education, which is more convenient and efficient. Among Chinese universities, only very few universities have set up administrative departments for general education, but most universities do not have relevant departments [2].

\subsection{Comparison of the development significance of general education}

In 1921, the doctoral thesis of Wuhan University "Research on General Education in Chinese Universities under the Vision of globalization", the German educator Max Weber's book "Rational Foundation and Basic Foundation of General Education" was published, marking the emergence of general education as an independent discipline, with a history of more than 90 years [3]. As an interdisciplinary discipline, general pedagogy makes full use of the theory, perspective and method of pedagogy, re-examine the problems of general education, and rapidly develops into a science, which is worth studying and learning.

\section{THE DIFFICULTIES IN THE IMPLEMENTATION OF GENERAL EDUCATION IN CHINA}

\subsection{Talent Training Objectives}

Huang and Chen argued that whether talent training aims at helping students' integrated development or educating them for future careers is a major dilemma faced by Chinese universities in the process of current educational development [4]. If a student has received education which aims at preparing for a career in universities but has not engaged in the career, then the education he or she ever received had little impact on his or her future development. If Chinese universities implement general education based on reading under the background of social attention to practicality, the implementations of education will be hindered. Therefore, how to balance these two factors is a major difficulty faced by Chinese universities.

\subsection{Curriculum Objectives}

Tang argues that general education should face the challenges of globalization and the information age [5]. Shi, Yu and Tian argued that although the curriculum objectives of universities in China are in line with the concept of cultivating students' integrated development, they need to be improved in terms of globalizations [6]. In the process of implementing general education, if Chinese universities cannot make the curriculum objectives international and conform to international characteristics, it will be difficult to enhance students' international consciousness, develop their international thinking, cultivate their international visions and improve their international quality. Therefore, whether the curriculum objectives can meet the requirements of globalization and face the challenges of globalization is a major difficulty faced by Chinese general education.

\subsection{Education Model}

Yi argues that Chinese universities of different types and levels have different educational resources. How to combine general education and professional education in the organizational system is a major difficulty [7]. Huang and Chen argue that what kind of education model is reasonable and how to manage and evaluate the general education curriculum is a major problem in the development of general education [4]. If general courses are specially set up, it is difficult for qualified Chinese universities to coordinate general courses and professional courses, set the sequence of the two, and adjust the faculty structure accordingly; if the general spirit is integrated into the professional curriculum, there should be more flexible and systematic professional teaching, and higher requirements for the cultivation of abilities

\subsection{Imperfect Curriculum System}

Shi, Kang and Tian argued that due to the short establishment time of some universities in China, they have not set up general education management centers independent of the educational administration system, and their management systems are relatively weak; although some universities have established independent management centers, their internal systems are chaotic, their levels are not clear and orderly, and their rights and responsibilities are not clear enough [6]. If Chinese universities cannot improve the curriculum system of general education, design a mature overall framework and systematize the management system, it will be difficult to promote the implementations and developments of general education. Pang argues that discipline training occupies a dominant position in modern universities. The organization in universities is generally divided according to the major, and there is no special department for general education [8]. If Chinese universities focus on professional education, always make it dominant, and ignore the overall planning and management of general education courses, then general education will be difficult to be valued by teachers and students, and the quality of education cannot be guaranteed.

\subsection{The Lack of High-quality Faculty and Curriculum Resources}

Huang and Chen argued that the lack of general 
education resources is mainly reflected in the lack of high-quality faculty and curriculum resources [4]. Liu, Chen and Li argue that the quality of faculty has a great impact on the implementation of general education courses [9]. Teachers are greatly affected by professional education and do not pay enough attention to general education. They regard general education courses as a supplement to professional courses, which affects the quality of education.

\subsection{Lack of Absorption of Foreign Experience and Independent Innovation}

$\mathrm{Lu}$ argues that the western experience in curriculum teaching is worthy of reference by Chinese universities. However, in the actual teaching process, Chinese Universities' learning of foreign advanced teaching experience is not comprehensive and in-depth [7]. Shi, Kang and Tian argue "the initial development of general education courses in Chinese universities was established on the basis of learning and imitating comprehensive universities such as Harvard University and Duke University, so the internal homogeneity is strong, and the degree of innovation is not high [6]." If Chinese universities cannot fully and deeply absorb the advanced teaching experience of the west and carry out independent innovation in combination with their development status and objectives, they will not be able to achieve good results in the implementation of general education. The lack of absorption of foreign experience and independent innovation is a major difficulty faced by Chinese general education.

\section{AN ANALYSIS OF THE REASONS AND PROSPECTS FOR THE DEVELOPMENT OF GENERAL EDUCATION IN CHINA}

\subsection{Reasons for Incompatibility at the Initial Stage of Introduction}

Why has general education, the mainstream of European and American universities, repeatedly fallen flat since it was introduced into China by Peking University, Fudan University, and other universities around 2000? Richard Levin, the President of Yale University, pointed out that "Every education mode has cultural adaptability, so does the general education model. As an education model with a long history in the United States, general education is a brand-new education concept developed in a foreign culture for China. Therefore, it is difficult to copy it to China without any changes [10]."

In fact, general education is not only imported to China. As early as the traditional Chinese private school teaching, there was the concept of "scholar, gentleman, generalist." The six arts of rites - music, archery, charioteering, calligraphy, and mathematics also conform to the idea of cultivating people in an all-around way in general education. $\mathrm{Li}$, deputy dean of Xinya College of Tsinghua University, states that "There is a general education factor in Traditional Chinese culture, but different from American universities, the general education curriculum system of Chinese universities is not original but added to the curriculum system in the past decade, which brings a problem of compatibility between the old and new curriculum systems. The consensus of ideas, the allocation of resources, class hours, and teachers have become urgent problems to be solved in general education development. At present, many universities have several modules or groups of general education courses, but the key is whom to invite, how to teach the course, and what purpose the teaching should achieve, which need to make great efforts to breakthrough [11]." However, due to the needs of the construction of The Times, the early structure of higher education has been specialized in the teaching of the division of labor for a long time, which is oriented to a few elite groups. However, the introduction and implementation of general education coincided with the gradual popularization of China's higher education. The number of undergraduate students increased sharply, and there were specific problems in matching teachers and teaching resources. At this time, the conflicts between the old and new systems intensified the discomfort of general education in China at the initial stage of its introduction.

\subsection{Reasons for inappropriate development stages}

Wen from the Department of Chinese Language and Literature of Peking University pointed out: "Nowadays universities are in a hurry to get more projects and achieve more results to catch up with the first-class. 'Shouting innovation' every day, investing a little money in the hope of immediate results, in fact, or instrumental thinking. Many university decision-makers show respect for science on the surface, but they are 'practical first' and the so-called 'respect' is limited to the field of tools and empirical evidence. Restricted by such instrumental thinking, it is difficult for universities to become spiritual highlands. The talents they train are inevitably narrow in vision and lack of innovation ability [12]." It is the embodiment of the university's eagerness to make achievements at the practical level of general education. Therefore, he believes that the implementation of general education needs to "force us to change the way of thinking: no matter what universities, they should focus on holistic education, liberal education, and then professional education. Moreover, the professional education process should not forget general education to integrate professional education and general education." 


\subsection{The Future Development Direction of General Education in China}

From the initial conflict of the old and new system to the development stage of quick buck run counter to the general education purpose, general education development in colleges and universities in China still has a long way to go. The development of general education systems in Europe and the United States has also gone through thousands of years. The practice and improvement of generations of educators require the unremitting efforts of Chinese educators to develop a general education system that fits China's national conditions. It also needs the unremitting efforts of Chinese educators. Lin believes that general education needs to break through the following points to continue to develop in colleges and universities in China based on the following bully points:

The aim of training should be whole-person education.

The philosophy should be based on Chinese culture.

There should be sufficient freedom and space in the curriculum structure.

The elitism should be removed.

The practice model suitable for different levels and types of colleges should be established.

A quality guarantee system should be established.

A complete incentive and evaluation mechanism.

Nowadays, the importance of general education is self-evident, but how to carry out the best in line with China's national conditions requires generations of Chinese educators to "search from top to bottom [10]."

\section{CONCLUSION}

China is in the policy of "double burden reduction" of primary and secondary education. With the gradual implementation of the policy, the development and popularization of general education in Chinese colleges and universities is very necessary and of great significance to every student who is about to receive higher education. In recent years, more and more experts and scholars at home and abroad have studied on the interaction of general education in China and the West, and have extended application and development towards the level of interactive communication. This shows that more and more experts and scholars begin to pay attention to the importance of education and interactivity in general education. However, it is difficult for the comprehensive research or development of general education in Chinese universities to develop into an independent discipline, because it involves many education and culture, various ways of interaction and communication and the degree of integration among cultures, which need to be further explored and interpreted by scholars. Therefore, the following aspects are of great necessity, in which truly make general education more suitable for Chinese students, establish a clear student training direction, set up clear curriculum objectives, improve teachers' understanding of general education, and have more departments related to general education.

\section{REFERENCES}

[1] X. Y. Wang, S. S. Sheng. American University General Education Models, Challenges and Strategies, Institute of Education, Tsinghua University, Beijing, 2015.

[2] C. Liang. Research in Universities' General Education of implement and strategy, 2017.

[3] L. P. Zhang. A Study on the General Education in China higher education in the Context of Globalization, Wuhan University, 2014.

[4] M. Huang, Y.H. Chen. Comparative Research on the Practice of General Education in China and Foreign World-class Universities[J], Meitan Higher Education, 2019.

[5] L. Tang. Sinicization and Orientation of General Education[N], Guangming Daily, 2013.

[6] M.H. Shi, Y.K. Kang, Y.Y. Tian. The Realistic Pattern and Optimization Path of General Courses in Research Universities -- A Comparative Study Based on Three Types of General Courses in Research Universities[J], Education Exploration, 2019.

[7] Y. Lu, B. Chen. Three Challenges for General Education[N], China Science Daily, 2021.

[8] H.S. Pang. The Dilemma and Outlet of General Education Curriculum Construction[J], Jiangsu Higher Education, 2010.

[9] T. Liu, X.P. Chen, P.K. Li. A Comparative Study on the Practice of General Education in Some Chinese and American Universities[J], Heilongjiang Higher Education Research Institute, 2004.

[10] J. Lin. Localization of General Education: Focusing on Adaptation and Innovation [N], China Education Daily, 2010.

[11] Q. H. Wang. How to Take the Road of General Education [N], Guangming Daily, 2017.

[12] R. M. Wen. General Education Courses cannot be satisfied with "Knowledge Platter" [N], Guangming Daily, 2013. 